\title{
HACIA UNA RECONSTRUCCIÓN DE LA RAZÓN PEDAGÓGICA
}

\section{Toward a reconstruction of pedagogical reason}

\section{Vers une reconstruction de la raison pedagogique}

\author{
Vicent GozÁlvez PÉREZ \\ Universidad de Valencia. Facultad de Filosofía y Ciencias de la Educación. \\ Departamento de Teoría de la Educación. Avda. Blasco Ibáñez, 30. \\ 46010 Valencia. Correo-e:vicent.gozalvez@uv.es
}

Fecha de recepción: marzo de 2010

Fecha de aceptación definitiva: julio de 2010

Biblid [(1130-3743) 22, 2-2010, 19-42]

\section{RESUMEN}

La pedagogía, como disciplina científica y filosófica racional acerca de la educación, ha visto cuestionada su legitimidad tras la llegada de la posmodernidad. Ésta ha traído consigo la sospecha de la racionalidad y los valores que han regulado tradicionalmente la actividad educativa. Pero, ¿con qué fuerza van a sostener los pedagogos la racionalidad de sus propuestas? ¿Sigue siendo la educación un ámbito propicio para el cultivo de la razón en los educandos? Cuestiones decisivas como éstas están reclamando la reconstrucción de la razón pedagógica, reconstrucción que ha de servirse de los escombros de la deconstrucción posmoderna, eso sí, sin renunciar al espíritu de la modernidad democrática y a buena parte de su legado axiológico.

Palabras clave: racionalidad pedagógica, modernidad, posmodernidad, democracia, teoría del caos. 


\section{SUMMARY}

The legitimacy of pedagogy, as scientific and philosophical discipline about education, has been questioned after the arrival of post-modernity. Postmodernity has suspected about traditional rationality and values of educational activity. But, at which point are going the pedagogues to defend the rationality of their proposals? Is still education the sphere of reason's development in the students? Decisive questions like these are demanding the reconstruction of pedagogical reason, reconstruction which has to use the rubbles of postmodern deconstruction, but otherwise cannot reject democratic modernity and a great amount of its axiological legacy.

Key words: pedagogical rationality, modernity, postmodernity, democracy, chaos', theory.

\section{SOMMAIRE}

La pédagogie, comme discipline scientifique et philosophique rationnelle sur l'éducation, a vu contestée sa légitimité après l'arrivée de la postmodernité. Celle-ci a apporté avec elle la suspicion de la rationalité et les valeurs qui ont réglementé traditionnellement l'activité éducative. Mais, de quelle force vont-ils soutenir les pédagogues la rationalité de leurs propositions? L'éducation reste-t-elle un milieu propice à la culture de la raison dans l'apprentissage? Des questions décisives telles que celles-ci sont en train de réclamer la reconstruction de la raison pédagogique, reconstruction qui doit utiliser les décombres de la déconstruction postmoderne, mais bien sûr, sans renoncer à l'esprit de la modernité démocratique et à une bonne partie de son héritage axiologique.

Mots clés: rationalité pédagogique, modernité, postmodernité, démocratie, théorie du chaos.

\section{INTRODUCCIÓN}

Hablar del concepto de razón pedagógica, tal como pretendo en este artículo, supone un intento por abordar nuevamente la compleja cuestión epistemológica del sentido y el papel de la racionalidad en la esfera educativa, racionalidad puesta en tela de juicio y sometida a una profunda revisión tras la irrupción de la posmodernidad.

¿Existe algo así como la razón pedagógica? La respuesta puede ser afirmativa en la medida en que también concedamos rango de existencia a maleables construcciones conceptuales como la de razón dialógica, razón tecnológica, razón estratégica, razón prudencial, razón utilitaria, etc., en última instancia construcciones de la inteligencia para poner orden, favorecer el entendimiento y funcionar operativamente en distintos ámbitos de la acción humana. Cabe hablar de la razón pedagógica como motor del quehacer de los pedagogos, de los científicos, teóricos y profesionales de la educación; pero igualmente, un nuevo modelo de 
racionalidad es el que conviene ir perfilando como una de las competencias primordiales a potenciar en el alumnado, máxime cuando se imponen nuevos modos de comprensión de la realidad en el nuevo entorno tecnocomunicado.

La reflexión sobre el sentido y la legitimidad de la razón pedagógica es al cabo una cuestión fundamental, la que se refiere a uno de los fundamentos del conocimiento pedagógico. Aunque el término no suele aparecer explícitamente, la razón pedagógica es un supuesto básico en el discurso de la pedagogía y en las investigaciones cuyo objeto es el fenómeno educativo, fenómeno peculiar por su doble condición como hecho descriptible racionalmente -científica y hermenéuticamente- y como fenómeno normativo racionalmente analizable.

En este artículo me propongo contribuir de algún modo a la reconstrucción de la razón pedagógica, una vez deconstruida ésta por parte de la pedagogía posmoderna (Finkielkraut, 1987; Colom y Mèlich, 1994; Hargreaves, 1999; Colom, 2002; Ibáñez, 2008, etc.), posmodernidad que, como argumentaré, tiene un indudable valor en el ámbito educativo como denuncia de los abusos cometidos por una forma de entender la racionalidad excesivamente rígida, burocratizada, esclerotizada y autoritaria. Dicho de otro modo, la deconstrucción del conocimiento pedagógico acaecida en el seno de la posmodernidad es un elemento clave para una redefinición -que no negación- de la racionalidad pedagógica, aunque quizás sea una etapa que apunte a un nuevo modo de entender, reconstructivamente, el conocimiento pedagógico.

\section{La RaCiOnalidad MODERNA EN TELA DE JUiCiO}

Asistimos a un momento histórico en el que aún colea el discurso de la posmodernidad. Tópicos como la muerte del hombre (Nietzsche y más tarde Foucault), la deconstrucción del conocimiento de la realidad (Derrida), la estructura o el sistema por encima del hombre (de Lévi-Strauss a Luhmann), la muerte de los grandes relatos (Lyotard), la disolución de fundamentos metafísicos (Heidegger o Vattimo), la era del pensamiento débil, el relativismo epistemológico y la moral indolora (Lipovetsky)... siguen más o menos vigentes, aún se respiran en el ambiente y, lo que más nos interesa, tienen evidentes repercusiones en la esfera de la educación.

En general, se puede afirmar que desde la óptica de la posmodernidad no tiene demasiado sentido afirmar la existencia de una razón pedagógica, ni de cualquier otro tipo de racionalidad en el ámbito de las ciencias humanas. Pues, justamente, uno de los tópicos definitorios de la posmodernidad es la disolución del sujeto - del hombre- y de los grandes relatos de la tradición moderna occidental, entre ellos la razón que, como constructo absoluto que se supone que es, empobrece y tiraniza la vida.

Sin embargo, y más allá del llamado irracionalismo posmoderno (Sebreli, 2007), la pedagogía ha de seguir preguntándose por el sentido de la educación de un modo argumentativo -dialógico-, reflexionando sobre los fines a los que 
racionalmente cabe aspirar y sobre los mejores -más racionales- medios para alcanzarlos, desarticulando así la fuerza y operatividad del discurso irracionalista aplicado a lo educativo. Para ello es preciso redescubrir los lindes de una razón pedagógica a partir de una modernidad revisada y reeditada.

De todos modos, las críticas de la posmodernidad aplicada a la educación han de ser aprovechadas para un enriquecimiento de la razón pedagógica, más que como mecanismo para su disolución definitiva. En el fondo, tal como defenderé, la posmodernidad no pretende anular totalmente la fuerza de la racionalidad aplicada al ámbito de las ciencias humanas y la pedagogía, sino deconstruir -desactivarun modo de entender el conocimiento pedagógico tan encorsetado que deviene obsoleto e inoperante. La moda del antihumanismo posmoderno, sin embargo, ha de dejar paso a un nuevo humanismo crítico, desligado, eso sí, de rigideces y dogmatismos de antaño, aunque es de justicia recordar que la razón moderna ilustrada, si nos atenemos a su espíritu fundacional, no pretendía erigirse ni rígida ni dogmáticamente, más bien todo lo contrario (Todorov, 2008).

La racionalidad moderna puede renacer fortalecida si la posmodernidad se entiende no como negación sino como revisión del papel otorgado a la razón en la sociedad, sobre todo en la educación. Pues en educación no es precisamente irracionalidad, improvisación y confusión lo que nos falta, al menos en una sociedad democrática que trata de gestionar de la mejor manera las libertades de todos. La posmoderna pedagogía del caos puede ser aprovechada, como veremos, más que como alegato a la irracionalidad educativa, como revisión edificante y necesaria del sentido y alcance de la racionalidad moderna: como acicate para la reconstrucción de una nueva razón pedagógica capaz de superar errores y dinámicas viciadas, por ejemplo, la burocratización esclerotizada y la planificación educativa fría e inamovible, tan ajena a la flexibilidad y los cambios como renuente respecto de la argumentación participativa de todos los afectados.

Algo conviene aprender de la posmodernidad: puede que la búsqueda de fundamentos metafísicos absolutos y últimos en la educación sea, en efecto, una búsqueda falaz e infructuosa. Ahora bien y como argumentaré, no puede concebirse una educación íntegra y aceptable en Estados democráticos de derecho sin el recurso a ciertos fundamentos referenciales sólidos, que no rígidos o unilineales. Huir de fundamentalismos no se ha de hacer necesariamente a costa de sacrificar todo fundamento, sobre todo si entendemos que la deliberación en sociedades democráticas requiere de ciertos presupuestos fundamentales (Habermas, 1986; Cortina, 1986).

El nihilismo posmoderno ha de ser transformado, tras el terremoto posmoderno, en hermenéutica crítica, en método de interpretación abierta al discurso argumentativo y a parámetros que han de ser clarificados y justificados previamente. Hoy en día no se puede ofrecer un modelo educativo sin este ejercicio de clarificación y justificación previa de aquellos supuestos que permiten un acercamiento racional al mismo. Pues hablar de la razón pedagógica es hablar de la disposición elemental para la argumentación y los acuerdos mínimos en materia educativa, algo que de facto es una de las aspiraciones definitorias de la pedagogía. 


\section{DECONSTRUIR LA MODERNIDAD COMO RACIONALIDAD BUROCRÁTICA}

La defensa de una racionalidad pedagógica dinámica, integradora, permeable y democrática ha de contar con la deconstrucción posmoderna del conocimiento pedagógico, pero como crítica previa a una posterior y necesaria tarea de reconstrucción. En este texto y con este propósito lanzo una piedra a favor de la reconstrucción de tal conocimiento pedagógico acudiendo a las fuentes originarias de la modernidad, por ejemplo, a la tradición ilustrada, al impulso ético y político original como movimiento pedagógico emancipatorio y transformador; tradición e impulso plenamente actuales a pesar de la versión positivista y del anquilosamiento burocrático de posteriores momentos históricos.

Este proceso de necesaria revisión de la razón pedagógica ha sido llevado a cabo, en los últimos años y en nuestro entorno intelectual, por el profesor Colom (2002). Una de sus obras más conocidas precisamente lleva un título bien significativo: La (de)construcción del conocimiento pedagógico. Se trata de un esfuerzo epistemológico por dar la vuelta y socavar la teoría de la educación que parte de posiciones modernas tradicionales, en el sentido de burocratizadas, rígidas o verticales, posiciones ancladas en una visión predeterminada de la realidad y que parten de certezas inamovibles a las que la teoría de la educación había de acogerse. Sin embargo, la formulación en paréntesis de la partícula negativa "de» en el título de la citada obra deja entrever que tras la destrucción y crítica de ciertos modelos epistemológicos anteriores se deja la puerta abierta a una nueva construcción, cuyo horizonte está pendiente de trazarse de modo más explícito. Tras la de-construcción de la epistemología pedagógica moderna, tras las cenizas dejadas por una visión obsolescente e ineficaz de la modernidad, cabe iniciar el proceso reconstructivo del conocimiento pedagógico, eso sí, desde nuevas luces y nuevos criterios argumentativa y dialógicamente establecidos.

Este proceso reconstructivo nos obliga, no obstante, a acudir al origen: ¿es la modernidad tal como se forjó inicialmente, equiparable en esencia a la burocratización rígida de la sociedad? Es cierto que la modernidad ilustrada y el impulso educativo que la propulsaba han sido identificados en ciertos momentos con la planificación administrativa rigurosa. Son varios los autores que, desde una perspectiva posmoderna, defienden que el binomio modernidad-rigidez burocrática constituye una equivalencia incuestionable (Colom, Mèlich, Hargreaves o Terrén).

Tal identificación procede, mucho antes, del enfoque sociológico de Max Weber. Para el sociólogo alemán, el impulso ético-político de la Ilustración, basado en la realización práctica de la libertad, fue gradualmente adulterado por una ordenación mecánica y jerárquica de lo social. En palabras de E. Terrén,

la progresiva consolidación de lo burocrático no le permitía [a Weber] albergar apenas esperanza alguna de que las instituciones educativas pudieran alentar una cultura ético-política capaz de revivir un impulso ideal de libertad e iniciativa individual, capaz de compensar el trágico destino de un "aniquilamiento mecánico" (Terrén, 1999, 88). 
He aquí el motivo de que la educación moderna aparezca en Weber como una institución políticamente muerta, en la que el espíritu ilustrado inicial "queda reducido a un mero vestigio, una institución desencantada que ha agotado su capacidad de impulso utópico, ahogada en la coacción objetiva que deriva de su propio desarrollo" (op. cit., 89). Así, la modernidad estaba abocada irremisiblemente, según Weber, a un agotamiento de sus iniciales aspiraciones éticas.

Ahora bien, la interpretación weberiana de la modernidad, asumida por Colom (2002) o Hargreaves (1999), puede ser matizada sobre todo cuando entendemos que la modernidad, en el campo que nos interesa, ha supuesto una defensa pedagógica válida e ineludible de tradiciones educativas radicalmente democráticas. La pedagogía moderna, desde Rousseau y Pestalozzi hasta Ferrer i Guàrdia, Dewey, Piaget o Kohlberg, por citar sólo a unos pocos y a pesar de las enormes diferencias, responde más al reto de renovación ética y emancipación social que al proyecto de cosificación racional-burocrática (de planificación jerárquica y "de despacho") de los planes educativos. No sería justo olvidar que la modernidad ilustrada supuso, en el ámbito ético y pedagógico, una firme apuesta por la emancipación y la humanización de la sociedad.

Emancipación en el sentido de defensa radical de las libertades individuales y civiles de las personas, de la autonomía intelectual y moral de las gentes y los pueblos frente a poderes tiránicos externos o frente a la esclavitud de la ignorancia y los prejuicios infundados. Humanización en el sentido de apuesta por la igual dignidad humana en términos universales, partiendo de la consideración a las personas como fines en sí mismos y no como objetos o instrumentos al servicio de otros (usando la terminología kantiana). También como reivindicación clara de los derechos y deberes del hombre, de la solidaridad y ayuda mutua en tanto que seres vulnerables que comparten una común condición (Herder, 2007). La modernidad ilustrada ha de ser entendida, antes que nada, como el intento de enarbolar racionalmente un proyecto ético y político que, en las actuales democracias, sigue teniendo plena vigencia, lo cual no obsta para afirmar que la ética de la convicción y los principios universales nacida en su seno tenga que ser complementada con una ética de la responsabilidad y el cuidado por el otro en su singularidad (Mèlich y Bárcena, 1999).

De todos modos, la crítica a una burocracia educativa inflexible, autoritaria, formalista hasta el absurdo, no participativa ni fluida (que impide la perspectiva y la participación de los afectados), es una crítica lícita en el sentido de que desde una burocracia educativa asfixiante no puede dibujarse la acción de una auténtica racionalidad pedagógica. Esta crítica es lícita y saludable, pero en términos de una modernidad releída y recuperada, no en términos de una posmodernidad que socava la razón y la posibilidad de buen entendimiento en cuestiones educativas. Asimismo, la necesaria renuncia a relatos metafísicos absolutos no habría de conducir a la ausencia de criterios y valores desde los que orientar la acción educativa. 


\section{LA DECONSTRUCCIÓN COMO PASO PREVIO A LA RECONSTRUCCIÓN}

El proceso de deconstrucción del conocimiento pedagógico tiene sus orígenes en la obra de Nietzsche, como pionero en la crítica a los valores absolutos y al Dios de la verdad occidental:

En consecuencia, el hombre -el de la modernidad- acomodado a sus creencias, orientado por la verdad y lo absoluto, también ha muerto. De ahí que se diga que tras la modernidad se expresa la filosofía de la deconstrucción, por utilizar la expresión de Derrida. Dios, el hombre, la realidad, dejan de ser verdades inmanentes porque el sujeto trascendente de Descartes y Kant hace tiempo que dejó de existir. Hay pues que deconstruir al hombre, retornarlo a su desnudez axiológica (Colom, 2002, 88).

El nuevo hombre de la posmodernidad, dice Colom, se adhiere a su etimología (humus), y recupera su terralidad, ausente de valores. Es capaz de romper con las falacias humanistas de la tradición moderna (verdad, razón, fe, moral, valores, etc.). El nuevo hombre no requiere de los mitos de la razón para sobrevivir, de lo cual podemos legítimamente deducir que educar es un proceso que habría de hacerse eludiendo los valores, ya que "los valores además de no existir son innecesarios" (p. 88).

Este hombre nuevo (una especie de übermensch) es el hombre funcional, radicalmente pragmático, presentista y relativista, el hombre que desarrolla el pensamiento débil (Lyotard, Lipovetsky, Derrida, Finkielkraut, Vattimo...), guiado por una nueva lógica, la del deseo:

La tecnología ha posibilitado la inmediatez, la funcionalidad máxima y el pragmatismo radical. Esto ha hecho que el hombre haya relativizado lo absoluto, las verdades inamovibles y por tanto, que haya sustituido la lógica de la moralidad -la creencia en los grandes valores- y la lógica de la razón -la creencia en las grandes verdades- por la lógica de la necesidad -o la satisfacción del deseo (op. cit., 87).

Al no haber verdad, tampoco hay sentido, "con lo que tampoco es necesaria la razón", continúa el autor. ¿Qué queda al derrumbarse los "mitos de la razón", qué educación defender al desvanecerse incluso la ética? Afirma Colom, siguiendo a Luhmann, que "tras la modernidad... sólo se da el sistema, o sea, la estructura o verdadera arquitectura de soporte que permite que se dé la realidad que se está dando" (op. cit., 89).

Sin embargo, no pueden defenderse, en aras de la educación posmoderna, los presupuestos del posestructuralismo de Luhmann y al mismo tiempo apelar al vitalismo de Nietzsche, aunque ambos compartan un antihumanismo declarado. Así, para Luhmann la ciencia debe vivir al margen de la moral, sin dependencia de las creencias o posicionamientos axiológicos. Lo que se requiere para explicar la realidad no son los hombres ni las categorías humanísticas sino la teoría -la 
ambición de la teoría-, es decir, un constructo sobre la base de conceptos, modelos y conceptualizaciones: "Son los conceptos los que explican el mundo... sólo es real lo que puede explicarse y, en este caso, lo único que realmente existe es la teoría, o sea, la propia explicación" (Colom, 2002, 92). Ahora bien, esta fe en las construcciones conceptuales supone una vuelta a la modernidad pero en clave neopositivista, algo que pondría los pelos de punta al mismo Nietzsche. Para el filósofo alemán, el lenguaje conceptual no es sino la necrópolis de la intuición y la vida, una antropomorfización de lo percibido en donde los conceptos, al cabo simples metáforas, simplifican, enfrían y empobrecen la inasible realidad:

Quien está poseído por el hálito de esa frialdad apenas creerá que también el concepto, óseo y octogonal como un dado y, como éste, versátil, no sea a fin de cuentas sino como el residuo de una metáfora... Ahora bien, dentro de ese juego de dados de los conceptos se llama "verdad" a usar cada dado tal y como está designado; contar exactamente sus puntos, formar clasificaciones correctas y no violar nunca el orden de las castas ni los turnos de las clases de jerarquía (Nietzsche, 2005, 61).

Resulta difícil, en la configuración de la óptica posmoderna, conciliar la fe en un sistema sin hombres ni valores, construido e impregnado tan sólo de conceptos que forman un sistema (Luhmann), con la desconfianza en cualquier sistema científico sostenido por conceptos, tras aceptar que éstos atentan contra el mismo fluir inaprensible de la vida (Nietzsche). En la reconstrucción de la razón pedagógica podemos, no obstante, aprender de un extremo sin caer en el otro:

1) De la posmodernidad nietzscheana podemos abogar por una racionalización educativa revisable, ampliar el juego de dados y sus reglas, romper jerarquías y clasificaciones preestablecidas: configurar una razón abierta a las circunstancias, flexible para con los casos particulares, sensible a cambios y adaptaciones... Eso sí, la flexibilidad a la que se somete la razón no ha de quebrar ni disolver su quehacer y sentido, sus intentos por entender dialécticamente el fenómeno educativo y por proponer técnicas educativas eficaces.

2) De la posmodernidad luhmanniana, la razón pedagógica puede construir mediante conceptos un sistema o estructura científicamente constatable, pero siempre que la conceptualización sea permeable y que la constitución de tal sistema ni renuncie a finalidades éticamente aceptables ni a valores que orienten la comprensión y la acción educativa. Si se extirpa de modo abrupto lo moral y lo axiológico de la esfera de la educación, ésta se resiente hasta perder algo importante de lo que la identifica, aquello que la conforma como esa irrenunciable actividad humana que piensa no sólo acerca de lo que el hombre es sino sobre todo acerca de lo que puede legítimamente llegar a ser. 
Al fin y al cabo, la nueva modernidad dentro de la que cabe inscribir la razón pedagógica ha de recuperar la vitalidad de un humanismo crítico que es enemigo de la rigidez, apostando firmemente por la innovación, el movimiento y la complejidad. Un humanismo capaz de superar la "paranoia analítica de la modernidad", siguiendo la expresión de Colom $(2002,100)$, una paranoia que todo lo somete al orden, a la especialización y a la jerarquía. La especialización y el departamentalismo, la solución a base de recetas fáciles o simples ante problemas complejos no son sino fruto de una modernidad mal entendida. En educación, la modernidad no ha de significar -ni ha significado siempre- esquematizar situaciones como si el mundo educativo fuera una estructura simple, definible, ordenada, lineal. Como si en la esfera educativa las mismas causas produjeran los mismos efectos.

El enfoque posmoderno entiende que la racionalidad lineal y unilateral en que se ha basado la pedagogía moderna es una rémora para la construcción teórica de la educación. Desde la posmodernidad (vinculada, como veremos, a una pedagogía del caos) se denuncia la escuela moderna tradicional por bascular en una razón estructuradora, legaliforme, homogeneizadora y ciega ante hechos educativos complejos, inestables, contingentes e imprevistos (Ibáñez, 2008, 79). Pero una cosa es que un tipo de racionalidad empobrecida sea inoperante, y otra muy diferente que la razón, en educación, deje de tener completamente sentido. Un ejemplo, según Colom, de la inoperancia de cierto tipo de razón pedagógica, es la perplejidad con que la tradicional pedagogía contempla fenómenos nuevos y complejos como los de violencia escolar:

¿Qué dice, por ejemplo, la teoría pedagógica de la violencia escolar? En buena lid, nada, porque este fenómeno rompe su discurso, su linealidad, las certidumbres establecidas (op. cit., 99).

En estos últimos años, sin embargo, la teoría de la educación o la pedagogía ya no viven de espaldas a fenómenos disruptivos como el bullying o acoso escolar, la hiperactividad o la convivencia escolar en situaciones conflictivas. Al margen de la inmensa producción bibliográfica en torno a estos temas, lo cierto es que las dificultades a la hora de tratarlos y abordarlos no es motivo para desterrar de ellos cualquier rastro de discurso racional. Más bien, lo que están exigiendo las nuevas situaciones problemáticas en educación es más racionalidad en el sentido de más lucidez, más razón imaginativa, más compromiso intersubjetivo, sensato e inteligente, más acción coordinada y racionalmente consensuada a partir de experiencias anteriores y de parciales logros en situaciones similares. En suma, más razón dialógica e interdisciplinar, abierta a las aportaciones de otras ciencias humanas (sociología, pedagogía, psiquiatría...).

Ante problemas tan acuciantes como los mencionados, la perspectiva posmoderna apela a la operatividad de una nueva epistemología pedagógica basada en la teoría del caos (Colom, Adams y Rush, Bird, González Veiga o Hargreaves). ¿Cuál es la clave de tal epistemología? 


\section{Pedagogía del caos y ReCOnStrucción de la RAZÓn Pedagógica}

La nueva epistemología propuesta por la posmodernidad trata de hacer pie no tanto en una modernidad filosófica revisada sino en la teoría del caos procedente del campo de las matemáticas, la física y la meteorología (E. Lorenz o I. Prigogine). La teoría del caos, afín al principio de indeterminación de Heisenberg, aboga por la complejidad, la incertidumbre, la no linealidad, lo impredecible... que aplicado a las relaciones humanas se traduce en un reconocimiento de la libertad creativa.

Sin embargo, hay buenos argumentos para pensar que el gran enemigo de la modernidad no son la complejidad, la incertidumbre o el reconocimiento de la vida y de la inmensidad de lo humano, sino los dogmas empobrecedores, los prejuicios absurdos y cerrados a la crítica, las visiones que empequeñecen la vida de modo autoritario, doctrinario o impositivo: al menos así se desprende del programa de la Ilustración europea (Todorov, 2007). En efecto, la lucha contra los prejuicios y tradiciones opresoras es una de las más valiosas herencias del proyecto pedagógico ilustrado, a pesar de la interpretación weberiana acerca del destino posterior de tales aspiraciones. Pero una cosa es, como hizo Weber, criticar el anquilosamiento de la modernidad en educación, crítica que no niega la racionalidad emancipatoria sino que más bien la añora, y otra muy distinta es, tras constatar el fracaso de la modernidad ilustrada en la historia occidental, apoyarse en ello para desestimar por completo el discurso racional y afirmar la validez de lo irracional en el terreno educativo.

Al calor de la teoría del caos, se pregunta Colom, tras certificar el lado errático, discontinuo y no lineal de la realidad, quién puede a estas alturas atreverse a decir que la educación es un fenómeno lineal y predecible. Ésta es una de las preguntas cardinales de toda su argumentación. La respuesta negativa (nadie se atrevería, según él, a considerar así los fenómenos educativos) puede, sin embargo, ser precisada en el intento de recuperar la validez de la razón pedagógica: los fenómenos educativos no son enteramente predecibles, como si se tuvieran que ajustar a predicciones férreas e insoslayables, sobre todo debido al margen de libertad y a la complejidad de la conducta humana. Ahora bien, en las intervenciones educativas sí que hay un elemento de predicción probable y sobre todo deseable. Una proyección o predicción así se presupone en las intervenciones ante casos de hiperactividad, psicopatías, disfunciones psicomotoras, problemas en el desarrollo cognitivo y sociomoral, etc., intervenciones que se pretenden exitosas con más probabilidad a medida que avanzan los hallazgos científicos y tecnológicos en estos campos específicos. Avance que refleja el desarrollo de la razón aplicada a la educación como complemento a lo caótico e impredecible en este ámbito.

En fin, la insistencia posmoderna en lo caótico, impredecible, no lineal, etc., más que conducir a un irracionalismo pedagógico, contribuye a una racionalidad pedagógica reformulada y enriquecida, a redescubrir la estabilidad inestable, el caos reordenado y la flexibilidad equilibrada en la esfera educativa. Todo esto vale 
siempre que ayude a entender y afrontar mejor un fenómeno tan complejo como el de la educación. No obstante, hay que perfilar bien los términos y no confundir la complejidad (rasgo atribuible al fenómeno educativo) con la inestabilidad absoluta, ni el caos con un desorden categórico y definitivo (situación no aplicable a la educación sobre todo desde un punto de vista normativo). El mismo Colom (2001, 13) declara que no conviene identificar el caos con la desorganización.

La teoría del caos pretende generar modelos comprensivos de lo social y educativo. La racionalidad pedagógica se enriquece con el modelo caótico como referente explicativo y comprensivo de la realidad humana y educativa. Pero, ¿qué ocurre con los modelos normativos imprescindibles en el quehacer educativo? La teoría del caos, basada en la formulación de ecuaciones no lineales sobre procesos altamente sensibles a los cambios que afectan a sus condiciones iniciales (algo atribuible al mundo educativo), es un modelo útil en la nueva descripción de la naturaleza. Sin embargo, tal modelo comprensivo supone a nivel normativo el reconocimiento de la dialéctica entre realidades inciertas y proyectos estabilizadores, dialéctica que se traduce en una reformulación educativa basada en la innovación, la participación y en la interactividad del saber actual (op. cit., 21). Pero quizás convenga distinguir bien estos dos ámbitos, el de la descripción fáctica y el de la prescripción pedagógica, a menos que se quiera incurrir en un discurso falaz (en la famosa falacia naturalista, consistente en deducir lo normativo a partir de lo fáctico, el deber ser a partir del ser). Por ejemplo, la teoría del caos puede explicar el fenómeno de la violencia o el fracaso escolar en la escuela, pero se echa en falta un modelo justificado acerca de los valores que laten en el fondo de esta explicación: vale la pena exponer con buenos argumentos por qué la violencia es algo educativamente indeseable, o por qué el fracaso es realmente una situación a evitar. Cuando se afirma que el caos es mentalmente saludable (pues la salud mental pasa por asumir imágenes del yo no rígidas, sino adaptables y flexibles), se está presuponiendo el valor de la salud por encima de la enfermedad, igual que en educación se presupone el valor de la paz y el conocimiento por encima de la agresión y la ignorancia. ¿Cómo justificar desde la epistemología posmoderna del caos y las incertidumbres tales preferencias axiológicas? Quizás haga falta recurrir a planteamientos modernos desde la raíz, acudiendo a su formulación genuina y más acendrada.

La teoría del caos pretende recuperar, situados en un nivel más normativo, el ideal de la libertad creativa en la educación. De acuerdo, pero ¿cómo usar esta libertad?, ¿hacia dónde reconducirla o favorecerla en los educandos, y sobre todo por qué hacerlo así y no de otro modo? De esto no puede -ni pretende- dar cuenta exhaustivamente la teoría del caos ni la deconstrucción posmoderna. [Por cierto, el término "deconstrucción" es un término fetiche o palabra mágica que hizo fortuna en la esfera posmoderna desde su formulación por J. Derrida, si bien es cierto que este filósofo no llegó a perfilar exactamente su sentido: en un juego de confusiones, llegó incluso a afirmar en 1993 que "si existe algo así, se desarrolla en la experiencia de lo imposible». La deconstrucción descompone o desestabiliza 
supuestos tradicionales para recomponer una nueva perspectiva... que será inmediatamente deconstruida. No es hermenéutica, no hay interpretación válida, es un camino sin salida, una aporía, una "estrategia sin finalidad" (Sebreli, 2007). Desde tales presupuestos deconstructivos, la pedagogía habría de disolver cualquier fin, objetivo o propósito en la educación].

La libertad ha de ser actualizada del mejor modo posible (Cortina, Escámez y Pérez-Delgado, 1996), valiéndonos de la razón y la argumentación, al lado de proyectos éticamente interesantes (que interesen, que estén entre y sean reconocidos por los afectados), eso sí, sin negar la imprevisibilidad, pero asimismo buscando previsiones inteligibles y deseables. Ése es el dinamismo de la razón pedagógica en cuyos planteamientos teóricos no carecen de espacio casos disruptivos, ruidos o disonancias como el fracaso escolar, los problemas de disciplina en el aula o el variable éxito de una misma metodología en distintos contextos... Establecer lazos entre teoría y praxis constituye, de hecho, una de las más acuciantes tareas de la actual teoría de la educación (Gargallo, 2002; Naval, 2008), preocupación que no es nueva, sino que en la última década del pasado siglo ya era tema central en esta área de conocimiento (Aznar y Gargallo, 1999). Objetivo: unir razón y vida, comprender racionalmente la vida para orientarla del mejor modo y enriquecer con la complejidad de la vida los planteamientos de la razón discursiva. Se trata de alcanzar unos mínimos acuerdos teóricos próximos a la universalidad, que ayudan a comprender la realidad educativa y que dan sentido al discurso pedagógico mismo, acuerdos que, sin embargo, son revisables atendiendo a la diversidad de circunstancias vitales. Pero si todo es diversidad y fluir absoluto, caos inaprensible e incontrolable, si todo es particularidad de modo que dos realidades educativas nunca son comparables, entonces la pedagogía carece de la más mínima racionalidad y la muerte de la pedagogía es su destino lógicamente insoslayable.

No es ésta, obviamente, la aspiración última de la epistemología posmoderna, al menos tal como es formulada por Colom. Más bien, de su propuesta se deduce que la razón pedagógica ha de ser revisada a fondo, aumentando y fortaleciendo los puentes entre teoría y praxis, pues como él mismo afirma ya es hora de acabar con "teóricos que no practican ni prácticos que no teorizan. En este sentido es urgente y necesario retornar de alguna manera la lógica a nuestros centros y a nosotros mismos..." (Colom, 2002, 161). Con afirmaciones como éstas, se deduce que tras la deconstrucción se impone una reconstrucción epistemológica, una nueva lógica -una nueva razón pedagógica- abierta de lleno a la cotidianeidad y a su caótico y complejísimo devenir. Urge, así, una reflexión constructiva y enriquecida con el devenir vital, capaz de enlazar la teoría con la praxis educativa.

En realidad, la teoría del caos ha de ser interpretada como una metateoría de la educación, o mejor, una metaepistemología creadora de un nuevo discurso racional y un nuevo fundamento en la pedagogía: 
Su pretensión (la de la teoría del caos) es dar conocimiento acerca del tipo de conocimiento que corresponde a la educación... En la teoría del caos, la cuestión adquiere nuevas dimensiones, pues sin negar la carga ideológica que también posee, no hay duda de que los grados de objetividad y de discurso racional que nos aportan sus correlatos, aproxima las ciencias sociales $-\mathrm{y}$ entre ellas a las ciencias de la educación- a posiciones de fundamentación disciplinaria de mayor rango o nivel (Colom, 2002, 166).

De este modo, la teoría del caos, lejos de disolver el discurso racional como pareciera, ayuda a recuperarlo alentando nuevas formas de pensar la realidad y proponiendo un modelo crítico, demoledor de la tradición, difícilmente adaptado a dogmas y normativas. Lo importante, desde la nueva epistemología, es construir tras la deconstrucción, crear conocimiento tras el conocimiento desestabilizador, crear un nuevo orden tras el caos: "Quizás la teoría del caos, como ya hemos anunciado, no sólo deconstruye la teoría sino que realmente puede coadyuvar a la construcción de un nuevo conocimiento acerca de la educación" (op. cit., 173). Faltaría profundizar en los términos y criterios de esa reconstrucción, algo a lo que pretendo invitar en este artículo.

Un ejemplo del caos en la educación nombrado con frecuencia por los pedagogos posmodernos es el hecho de que una misma intervención educativa puede obtener resultados diversos, ejemplo de la no linealidad, contingencia y carácter imprevisible de la educación. A pesar de ello y en aras de una nueva racionalidad pedagógica, la pedagogía posmoderna trata de explicar racionalmente esta imprevisibilidad. La divergencia se puede deber a factores como la motivación, el refuerzo, el interés, las actitudes, el entorno y las influencias familiares... Explicaciones que indican que el fenómeno educativo es complejo, pero -añadiríamosno totalmente caótico ni absolutamente imprevisible o azaroso. Es posible, pues, la argumentación racional y explicativa del caos, organizadora del caos, la capacidad para entendernos y ponernos de acuerdo en las intervenciones educativas que ayudarán a corregir tendencias indeseables en los educandos o a potenciar actitudes deseables y aceptables de cara a su formación, a su perfeccionamiento intelectual y profesional o a su autonomía moral.

Desde luego, la recurrente insistencia en el caos dentro del sistema educativo no puede deslizarse hacia una defensa de la arbitrariedad en la educación. El hecho de insistir en el desorden no ha de ser interpretado como un alegato a la improvisación arbitraria, improvisación alejada de lo que demandan en realidad los profesionales de la educación.

La nueva racionalidad pedagógica ha de dejar claro, de este modo, que los términos "caótico" y "complejo" no son homologables ni cabe homologarlos. No es lo mismo práctica educativa del caos, en el sentido de práctica que asume, integra, contempla y da cuenta del caos y la complejidad, que práctica caótica o aprendizaje caótico (hablando con propiedad, práctica o aprendizaje sin finalidad y sin criterios, carente del más mínimo orden y coherencia). Estas últimas son expresiones realmente problemáticas, en tanto que legitiman la tendencia a abjurar de la racionalidad 
pedagógica en los procesos educativos. Contemplar, aceptar y actuar desde el caos no significa que la acción educativa tenga que apostar por el caos, ni que desde un punto de vista prescriptivo sea deseable convertir lo educativo en el reino del desconcierto, la improvisación y la confusión ininteligible. En nuestra sociedad han desaparecido certezas inamovibles, y cabe por ello desarrollar educativamente una capacidad de adaptación flexible y siempre atenta a la movilidad de lo real y a las nuevas circunstancias. Aceptado esto, no hay que descartar el valor de algunas certezas y referentes más o menos sólidos tanto en la vida cívica democrática como en la esfera de la praxis educativa. Referentes que pueden surgir de la entropía, de la vivencia del desorden y del caos, pero como respuesta inteligente ante lo entrópico y lo caótico -respuesta que a su vez puede ser reformulada a partir de nuevas vivencias, por supuesto-.

De hecho, la pedagogía del caos asume la dialéctica orden-desorden, y afirma que la acción formativa y educativa trata de neutralizar la incertidumbre e imprevisibilidad:

Ésta es la dialéctica que debe incorporar la teoría de la educación: plantear una educación para la no previsibilidad (caos), al mismo tiempo que dotada de múltiples informaciones (orden). La información y la creatividad acaban con el orden, pero cuando lo creativo está asumido y la información es conocida, surge un nuevo orden que por serlo está llamado a sufrir las incidencias caóticas (Colom, 2001, 22).

En suma, el caos es un punto de partida, un elemento importante del sistema, pero no es el fin único o absoluto. El reconocimiento del caos -sobre todo de la complejidad y la incertidumbre- en educación no implica en absoluto que el único fin deseable sea una situación educativamente caótica -incierta-, sino la recuperación de soluciones para un equilibrio educativamente razonable y para un orden más rico y flexible. Pues incluso en los sistemas dinámicos de la física y la biología, y tras el flujo imprevisible del caos, emerge el orden (Strogatz, 2004; Gribbin, 2005; Bird, 2003). Recientemente ya están apareciendo modelos matemáticos que describen el modo de equilibrar y reordenar el caos en estos ámbitos (Sanjuán y Grebogi, 2010).

En cualquier caso, la epistemología posmoderna insiste en el éxito de la teoría del caos en el ámbito educativo de países como eEuu, puesto que desde tal teoría, y en contra de una metodología burocratizada y vertical, se ha producido una mejora de la práctica educativa. ¿Cómo? Por ejemplo, mediante el uso de metodologías participativas e interactivas, o mediante la apertura al cambio y a la innovación educativa, o a través de la comprensión mediadora ante casos disruptivos o violentos -canalizando los conflictos en vez de negarlos o reprimirlos-, o usando un modelo pedagógico flexible, espontaneísta, creativo y sensible a las diferencias (Colom, 2001; Ibáñez, 2008). Con lo cual podemos estar perfectamente de acuerdo, siempre que respondamos a algunos interrogantes: ¿qué es mejora de la práctica educativa?, ¿cuáles son los criterios que nos ayudan a reconocerla?, 
¿han de ser excluidos totalmente los criterios morales y axiológicos de raigambre moderna en este proceso de mejora? Cuestiones esenciales que invitan a decidir entre una modernidad revisada, que sigue confiando en la actividad del sujeto de la educación, o una deconstrucción en clave posmoderna, que duda del sujeto a favor del sistema.

\section{LA RECUPERACIÓN DEL SUJETO Y DEL SENTIDO DE ACTIVIDAD}

Es una tendencia bastante frecuente, en el entorno posmoderno, identificar la modernidad con la defensa de un sujeto activo cuyo fin es racionalizar la vida, en el sentido de imponerle un orden fijo, lineal, estático y cerrado. Un sujeto con mentalidad clínica y cerebral, estrecho de miras, reticente a la creatividad y a lo emocional:

La estrechez de miras, la decisión inflexible, las estructuras poco manejables, la planificación lineal, la falta de sensibilidad ante las necesidades cambiantes del cliente [del alumnado], el sacrificio de la emoción humana en beneficio de la eficacia clínica y la pérdida de sentidos significativos de comunidad han ido convirtiéndose en las características cada vez más evidentes y preocupantes de las últimas fases de la modernidad. Por eso, las organizaciones de la modernidad, con sus estructuras burocráticas y formas jerárquicas de liderazgo, se ven sometidas a poderosas presiones para su transformación (Hargreaves, 1999, 61).

La creación moderna de un sujeto con actividad racional ha desembocado, según los pedagogos posmodernos, en la entronización de unas estructuras cognitivas que al cabo reducen o simplifican la vida, y por ende el fenómeno educativo. La deconstrucción del sujeto moderno se impone por propia exigencia histórica, o al menos la deconstrucción del sentido de actividad tal como se había fraguado desde el siglo XVIII. Por este motivo, la educación posmoderna habla de formar en lo aleatorio desde la creatividad, en lo imprevisible y lo complejo asumiendo el lado emocional de la persona.

Sin embargo, esta declaración de fe en las posibilidades del sujeto pone en tela de juicio la posmoderna deconstrucción del yo, cuestiona la conveniencia teórica de disolver al hombre como ser activo. De nuevo, tras la disolución del sujeto, tras la deconstrucción, se impone un proceso reconstructivo. La epistemología posmoderna ha de ser releída no como el intento de disolver al sujeto en su papel activo, sino en todo caso como paso previo y necesario a la hora de redefinir el concepto de actividad. Esta visión de la posmodernidad puede observarse, por ejemplo, en afirmaciones como "sólo se aprende si es el sujeto quien cognitivamente logra, desde la complejidad, interpretar y ordenar el conocimiento" (Colom, 2002, 190). En suma, ¿no vale la pena, a pesar de todo, recuperar al sujeto activo en tanto que creativo y autónomo racional y vitalmente? Desde una reconstrucción de la racionalidad pedagógica, que ahora nos interesa especialmente, y desde una relectura de la perspectiva posmoderna, parece que no puede haber educación sin 
un sujeto crítico, un sujeto que podríamos situar en la esfera teórica de una hermenéutica crítica y de un constructivismo pedagógico reformulado.

A su vez y recíprocamente, algunas prácticas educativas a las que alude la epistemología posmoderna son recomendables en sintonía con una teoría del caos... reordenado. Por ejemplo, el "aprendizaje en el laberinto", consistente en iniciar un proceso de aprendizaje partiendo de una situación no estructurada (caótica) y compleja, induce a que gradualmente sea el educando quien indague activamente, con esfuerzo y con la ayuda de materiales pertinentes, para clarificar y reordenar la cuestión o cuestiones propuestas. Se trata de un ejercicio de búsqueda de sentido, un ejercicio de hermenéutica activa, de investigación y memoria significativa (personal o en grupo). En este proceso se pueden usar diferentes recursos tecnológicos (textuales o hipertextuales), pues en la escuela, la tecnología debe servir como "instrumento para la liberación del hombre, consecuentemente, debe estar a su servicio, a fin de que sea más fácil lograr con ello sus objetivos" (Colom, 2002, 192). No podemos estar más de acuerdo, insistiendo en la tesis de que la tecnología comunicativa ha de ser considerada como instrumento al servicio de la emancipación moderna del sujeto.

La defensa educativa del sujeto activo, creativo, crítico y libre es, pues, un ideal que conecta necesariamente la epistemología posmoderna con la moderna, puesto que un alegato a favor de la libertad creativa, tan venerada por la posmodernidad, no es contrario al espíritu de la modernidad. No hay que olvidar que uno de los atributos esenciales de la misma fue la defensa cultural de las libertades de las que hoy gozamos, aunque únicamente se puede defender la libertad con sentido si se trata de una libertad reconocible igualmente en los demás. Para la escuela moderna no es preocupante la libertad del niño, sino todo lo contrario. La llamada educativa a la libertad supone un puente entre la pedagogía moderna y la posmoderna, un horizonte común al que sin duda la educación apunta, eso sí, siempre que entendamos la libertad en sentido amplio, incluyendo en ella valores como la responsabilidad, la reciprocidad, el desarrollo humano y cívico (Sen, 2000) o la no dominación (Pettit, 1999). Concepto de libertad al que difícilmente se opondría cualquier enfoque pedagógico democrático, más allá de la etiqueta con que se nos muestre.

Por cierto, otra de las estrategias educativas defendidas por la epistemología posmoderna, como el uso del hipertexto, es ofrecida como válida no sólo por su contribución a la reconstrucción cultural o intelectual a nivel cognitivo, sino porque "al mismo tiempo, se le integra [al educando] en una educación en valores, a través de la tolerancia, la solidaridad y el respeto a todas las razas" (Colom, 2002, 208). De manera que desde la pedagogía posmoderna sí que podemos hablar de planteamientos morales preestablecidos con los que iniciar el proceso de reconstrucción: se presuponen unos valores morales desde los cuales el niño puede erigir creativamente, emancipatoriamente, su personal proyecto de vida compatible con los proyectos ajenos. 
Asimismo, prácticas recomendadas por la pedagogía posmoderna, como la autogestión educativa, nos retrotraen al ideal moderno de autonomía y autodeterminación. Dicho de otro modo, tras el caos, o más allá de la complejidad arbitraria o azarosa, el sujeto ha de aprender a usar su racionalidad creativa (no puede haber racionalidad sin creatividad) para dar unidad, para alcanzar coherencia y sentido, para clarificar (ilustrar, arrojar luz sobre el oscuro caos) en aras del conocimiento y la interpretación inteligente.

\section{EDUCACIÓN Y ORDEN}

Las críticas actuales al orden racional en educación presuponen que la modernidad parte de y aboga por un orden cerrado, estático, inamovible, rígido, simple, lineal (cual encefalograma plano); un orden que resuena a despótico, jerárquico y feudal. ¿Es en verdad ése el sentido moderno del orden?

El hecho de que una parte de la modernidad se haya encarnado en la burocratización y racionalización institucional de la que hablara Weber no es suficiente motivo para reducir de esa manera el campo semántico de términos como "racionalidad" y "orden". La modernidad ilustrada ya es en sí misma un fenómeno complejo, como decíamos, un hervidero de propuestas para la emancipación enteramente variadas, desde la defensa de una ilustración radical y revolucionaria hasta las llamadas a la reforma moderada sin arrumbar con la tradición (Todorov, 2007). En todo caso, el orden que se desprende de la modernidad ilustrada es un orden fluyente, subversivo, liberador, racionalmente aceptable pero profundamente revisable.

¿Qué racionalidad pedagógica sería ésa, de qué modernidad hablaríamos, si expulsáramos la creatividad, el poder de la imaginación o el espacio de lo alternativo de su seno? No hay educación moderna sin tolerancia -uno de sus grandes temas- y sin aceptación de la variedad y diversidad de opciones de vida, siempre en el marco de las libertades y el respeto. Tampoco hay racionalidad pedagógica sin el recurso a la inteligencia creativa. Racionalidad y modernidad se oponen, más bien, a dogmatismo unilateral, a uniformidades absolutistas, a tradicionalismos herméticos y a prejuicios inamovibles. No tomar en cuenta esto es levantar una visión simplificada de la modernidad, algo que sin duda pueden haber hecho algunos de los que se decían sus representantes. Pero la modernidad en sentido amplio, como renovación crítica de la sociedad a partir del conocimiento, como aspiración a la emancipación y la dignificación moral, es un proyecto que, como afirma Habermas (1989), aún está pendiente de actualización plena. Un proyecto inacabado que no puede edificarse sin el recurso a la razón pedagógica, a una razón dialógica que trata de entender el hecho educativo para promover el lado más lúcido, cognitivamente creativo e inteligentemente cívico, de los educandos.

La educación, como proyecto de mejora y perfeccionamiento, puede ser ahora observada desde el prisma de una racionalidad vital, dialéctica, mancomunada, sensible a lo emocional pero también a lo prudente y lo sensato; una razón corporal y asimismo gestora de una convivencia prudente en el ámbito de la terralidad, 
ese humus o humanidad que todos compartimos y en el que todos -hoy más que nunca- estamos implicados. Pues sólo desde tal razón pedagógica valdrá la pena reordenar creadora y libremente la desorientación, el absurdo o el caos. Que el mundo, nuestro mundo globalizado, alberga -y celebra- la diversidad, es algo evidente. Ahora bien, que desde la educación valga la pena difundir un sentido de tolerancia sin límites, una aceptación de cualquier punto de vista por el mero hecho de ser diferente o diverso, eso ya es otra cuestión.

\section{Diversidad, TOLERANCIA Y TOLERANTISMO}

La pedagogía posmoderna ha sido pionera en la inclusión de la diversidad en educación, tratando de introducir lenguajes diferentes, discursos distintos a los oficiales o hegemónicos. Como afirma Mèlich $(2008,51)$, una educación posmoderna sería aquella en la que "maestros y alumnos están convencidos de que no existe un único lenguaje, o un lenguaje privilegiado. Nunca hay un lenguaje, sino múltiples y distintos". Dicho de otro modo, la realidad es pensada lingüísticamente y no hay un único lenguaje que tenga la clave para captarla en su esencialidad: no hay una única verdad, un único lenguaje que descubra o desvele lo real, por lo que "ni la verdad, ni el sentido, ni la realidad son absolutos, sino finitos, relativos a los múltiples contextos en que se manifiestan" (ibidem). La escuela posmoderna celebra, por tanto, el fenómeno de la diversidad (de creencias, cosmovisiones, culturas, perspectivas...), para lo cual el gran valor a difundir es el de la tolerancia hacia la alteridad, hacia lo diverso o diferente.

Romper con modelos rígidos y uniformes es, así lo entendemos, un logro pedagógico, sobre todo cuando en el mundo educativo supone un reconocimiento de la disparidad de ritmos de aprendizaje en los educandos, de intereses y motivaciones, de tradiciones culturales y circunstancias sociales, de capacidades $\mathrm{O}$ competencias previas, etc.

De acuerdo, pero ¿hasta qué punto ha de ser reconocida y exaltada la diferencia? ¿Qué sucede cuando nos encontramos con diferencias culturales atentatorias contra la dignidad de otros alumnos, o de los mismos profesionales de la educación? ¿Qué hacer cuando la perspectiva alternativa de algún alumno entorpece claramente las perspectivas y libertades de los demás? En este sentido se pregunta $\mathrm{O}$. Reboul $(2009,109)$ si un maestro que tiene que tratar con un alumno dominador, violento o fanático, puede dejar que éste oprima a los demás alumnos.

La escuela posmoderna se ha traducido en lo que Reboul denomina escuela del indiferentismo, en una filosofía que en Estados Unidos recibe el nombre de humanismo y en Europa el de no directividad. Según esta filosofía de la educación, cualquier valor que constriña o que sea susceptible de reprimir el deseo, la realización y la creatividad del individuo ha de ser eliminado de los programas educativos. Lo más importante, según esta corriente, es promover valores tales como la empatía, el desarrollo espontáneo, la aceptación incondicional de uno mismo y de los demás, la aceptación de las diferencias y lo diverso, valores que se 
pueden reagrupar bajo el nombre de "tolerancia" (Reboul, 2009, 108). Del mismo modo, el indiferentismo posmoderno conduce a la idea de que la escuela ha de trasmitir una cultura no para reflexionar, sino para vivir, eliminando con ello los tópicos de una educación tradicional (¿moderna?) basada en clasificaciones y jerarquías, en castigos y premios, en exámenes y evaluaciones..., en suma, en el orden al que hacíamos referencia en el apartado anterior.

Sin embargo, esta filosofía de la educación plantea algunas dudas. Por ejemplo, suprimir las evaluaciones supone eludir una de las funciones sociales de la escuela, supone negar el derecho que tiene la sociedad a fiarse de los diplomas que otorga (Reboul, 2009, 109). Por otro lado, supone eludir su función pedagógica, pues la escuela tiene la misión de enseñar, de garantizar el aprendizaje y de validar de algún modo que éste se ha producido efectivamente. La habilidad y el talento del pedagogo consiste, más que en eliminar las evaluaciones, en "encontrar cuál es el nivel de rigor que debe aplicar cuando evalúa" (op. cit., 110).

La escuela indiferentista apunta irremisiblemente a otro problema de fondo, el de los límites racionales a la tolerancia, problema filosófico que nos remite a otra cuestión, a saber, la del sentido y validez del relativismo, sobre todo en educación. Una cosa es aceptar la relatividad en el juego de la vida, y otra muy diferente deducir de ahí la validez del relativismo (perspectiva según la cual todo, por relativo, es igualmente válido). Del mismo modo, una cosa es aclamar en clave moderna el valor de la tolerancia (frente a los abusos de autoridad, frente a las imposiciones arbitrarias, frente a poderes tiránicos, etc.) y otra muy distinta caer en el tolerantismo, en la actitud consistente en tolerarlo sistemáticamente todo. Pues no hay que olvidar que la defensa ilustrada de la tolerancia supuso un cortafuegos decisivo ante el avance de los absolutismos y los dogmatismos, sobre todo los religiosos (tal era la pretensión de Locke o Voltaire), aunque la tolerancia no era en sí misma una referencia axiológica última, pues estaba al servicio de valores superiores como la justicia o la dignidad humana. A partir de ahí, la tolerancia había de estar razonablemente limitada por tales principios, de modo que cualquier oferta diversa o alternativa que supusiera un atentado contra la dignidad de las personas merecía no ser tolerada. Tales límites se disuelven en el contexto de la posmodernidad:

El relativismo posmoderno ha absolutizado la tolerancia, la ha convertido en el valor supremo de la democracia, cuando en realidad debe estar siempre gobernada por otra virtud superior, la justicia, que limita a su vez la propia tolerancia (Tejedor y Bonete, 2006, 15).

Curiosamente, cuando la tolerancia a la diversidad se presenta como valor último y definitivo, es fácil caer en un nuevo absolutismo, en la defensa de perspectivas que, por diferentes, han de ser toleradas aunque en su seno habiten la dominación o el trato vejatorio. Declaración relativista, afirmación absoluta de la tolerancia e indiferentismo parecen así ir de la mano en el marco de la posmodernidad. Sin embargo, la defensa de la tolerancia no tiene por qué caer en el tolerantismo, 
en actitud indiferente ante todo, en ausencia total de unas convicciones que nos permitan articular una crítica razonable y fundada a lo dado.

El peligro de la disolución posmoderna de referentes válidos para la crítica es, como decíamos, un apoyo del tolerantismo en la escuela, el cual conduce a otorgar exactamente el mismo valor o el mismo rango a los conocimientos o recomendaciones del docente que a las opiniones o creencias de los educandos, ya que en última instancia maestros y alumnos hablan lenguajes distintos e inconmensurables. Así, desde estos presupuestos no tendría por qué ser más "verdadero" o "justo" lo que dicen los maestros respecto de lo que dicen los alumnos. Con ello, sin embargo, la crisis de autoridad o los conflictos de convivencia están servidos, son prácticamente inevitables. El profesor pierde autoridad académica, moral o científica ante los alumnos desde tales planteamientos, alumnos que legítimamente -desde la perspectiva posmoderna- pueden recurrir al tópico relativista que reza "lo que tú nos cuentas es sólo tu opinión, que vale tanto como cualquier otra, la mía por ejemplo". Declaraciones como ésta o similares, lejos de ser una mera hipótesis lógica, son una realidad vivida y constatada por muchos profesionales de la docencia en su práctica cotidiana (Gallego y Antón, 2007; Pérez, 2009).

En cualquier caso hay que decir, en honor a la verdad, que no está cerrada la perspectiva posmoderna a la posibilidad de consensuar reglas éticas básicas, de articular un lenguaje común desde el cual podamos entendernos y construir la convivencia. No es la pedagogía posmoderna del todo reticente a una perspectiva ética universalista, siempre que no se deje por el camino la mirada de la particularidad o la individualidad -afirmación con la que podemos estar razonablemente de acuerdo-: "Los posicionamientos éticos, estéticos o políticos de una educación en la posmodernidad no renuncian a la universalidad (especialmente en el caso de la ética), pero sus educadores saben que no es posible ninguna afirmación universal al margen de la particularidad, o poniendo entre paréntesis lo particular" (Mèlich, 2008, 52).

No obstante y recíprocamente, podríamos responder que la atención educativa a lo diverso y particular es una acción válida siempre que no se formule al margen de la universalidad (del principio universal del trato igual o del de la igual dignidad de los alumnos), o poniendo entre paréntesis lo universal, tendencia que frecuentemente ha sido asociada a los planteamientos posmodernos.

Así, ante esta posibilidad, ante la marginación o desaparición de las pretensiones racionales de universalidad, ante la celebración posmoderna de la diversidad, surgen nuevas preguntas: ¿qué sucede cuando en una misma clase la variedad de intereses, lenguajes, perspectivas y de competencias previas es tan elevada que resulta inviable una mínima dinámica de grupo? Podríamos pensar que en tales casos es preciso recurrir a personal educativo de apoyo, a la destreza de los educadores en adaptaciones curriculares o a la fineza y habilidad para atender a cada cual en su individualidad sin menoscabar por ello el trato igual y digno que merece cada uno. Pero, ¿no son tales medidas racionalmente recomendables? Efectivamente, la gestión de la diversidad en el aula reclama una metodología y 
unas propuestas pedagógicas racionalmente aceptables, pues en última instancia el discurso pedagógico pretende fortalecer su estatus, sus postulados y principios, las orientaciones que de él emanan, etc., mediante buenos argumentos, mediante el establecimiento de un lenguaje común más allá del solipsismo de los lenguajes privados o particulares: en definitiva, mediante el buen uso de la razón pedagógica, con un uso no dogmático sino crítico, dialógico e intersubjetivo de la misma. Ésa es la nueva racionalidad pedagógica que, habiendo aprendido de la posmodernidad pero yendo más allá de ella, se va consolidando en el conjunto de investigaciones y reflexiones de la pedagogía. Se trata asimismo de una racionalidad sentimental o sentiente, o emocional, que contempla, se interesa, valora e incide educativamente en la dimensión sentimental del ser humano como ser cuya inteligencia misma no es computacional o cibernética, pues se trata de una inteligencia -de una razón-viva, imperfecta si se quiere, pero humana al fin y al cabo. Así es esa nueva racionalidad pedagógica que se ha gestado y se está afianzando tras el huracán posmoderno. Una racionalidad reconstruida con los pilares de la crítica, del diálogo, de la vida sentimental, y por supuesto de la atención a la práctica educativa, que es al fin y al cabo la meta y el referente último de la argumentación pedagógica. A ello nos dedicamos en el próximo apartado, en un intento de reconstruir el discurso racional de la pedagogía tras la quizás necesaria deconstrucción posmoderna.

\section{CONClusión: LOS PERFILES DE LA NUEVA RACIONALIDAD PEDAGÓGICA}

Recuperar o consolidar el papel que a la pedagogía corresponde en sociedades democráticas se ha de lograr a base de reforzar la racionalidad de su discurso, racionalidad que, bien en su dimensión empírica, bien en su dimensión reflexiva, se tendría que caracterizar, tal y como lo entiendo, por unos rasgos definitorios como los apuntados a lo largo de este artículo. De un modo provisional y sintético, se podrían formular así los rasgos fundamentales de esa racionalidad pedagógica que está siendo reconstruida tras las sacudidas deconstructivas de la posmodernidad:

a) Primero, la racionalidad ha de ser eminentemente crítica, abierta a nuevas perspectivas y a la discusión constante acerca de sus hallazgos o proposiciones (Popper, 2006). Una racionalidad que, por propia definición, renuncia a un modelo dogmático de discurso, cerrado en sí mismo e igualmente impermeable a la revisión argumentada.

b) Segundo, la racionalidad pedagógica ha de ser dialéctica más que analítica, es decir, abierta a la incertidumbre, la complejidad y los desórdenes de la realidad educativa (Colom, 2002; Núñez y Romero, 2003; Colom y Núñez, 2001; Santos y Guillaumín, 2006), pero en constante búsqueda de nuevas y mejores cotas de equilibrio y eficacia en la consecución de sus fines y valores. Su dimensión dialéctica le impulsa a reconocer como positivo lo innovador y participativo, pues la racionalidad pedagógica va articulando el discurso acerca de lo educativamente válido a partir del 
diálogo y la buena argumentación, siempre bajo condiciones mínimas de respeto, escucha activa, libertad y disposición a modificar puntos de vista propios, reconociendo asimismo el valor de los ajenos (Habermas, 1989, 2003). Una razón monológica, cerrada a otras perspectivas y al intercambio de argumentos, es simplemente una razón fraudulenta, una racionalidad que viola los mismos principios que la definen.

c) En tercer lugar, la racionalidad pedagógica ha de ser una razón sentimental, emocionalmente matizada, es decir, receptiva al universo de sentimientos y emociones que tanto ayudan a entender la educación humana (Cortina, 2007; Asensio, García, Núñez y Larrosa, 2006). La racionalidad pedagógica no puede constituirse de espaldas a esa dimensión del ser humano, ni puede ignorarla a la hora de proponer fines y métodos educativos, máxime desde la certeza de que ni los educadores ni los educandos son seres computacionales cuya inteligencia funciona al modo de un superordenador complejísimo pero frío emocionalmente.

d) Cuarto, la racionalidad pedagógica ha de ser histórica: no ha de erigirse de un modo abstracto y descontextualizado, sino que debe reconocer el peso del lenguaje, de la cultura y la historia en su peculiar modo de funcionar y regirse, sobre todo cuando se ocupa de un fenómeno tan cultural como la educación, tal y como defiende el comunitarismo actual (Gozálvez, 2000). Eso no significa que la razón pedagógica tenga que renunciar a la universalidad de sus propuestas, al valor de la objetividad o intersubjetividad en su discurso - en la línea de la segunda modernidad representada por Habermas-. Más bien significa que junto a la pretensión de universalidad, la pedagogía ha de contemplar los aspectos peculiares de cada alumno y ha de reconocer de algún modo la carga cultural y el valor del contexto particular en la misma discusión racional acerca de lo educativamente deseable.

e) Finalmente, la racionalidad pedagógica ha de ser práctica, inspirada por y dirigida en último término a la praxis educativa (Escámez, 1992). En este orden de cosas, la filosofía de la educación ha de ser considerada como una actividad intelectual que prioritariamente se debe ocupar de problemas relativos a la acción educativa. En ese propósito constante de vincular la teoría con la práctica, la filosofía de la educación ha de superar (1) los efectos negativos de una pedagogía positivista, preocupada tan sólo de comprobar empíricamente el funcionamiento de distintos modelos educativos sin ninguna reflexión teórica de fondo, y (2) la perversión que supone un enfoque filosófico especulativo, basado en proposiciones tan abstractas, generales y desencarnadas que es imposible comprobarlas o validarlas racionalmente, proposiciones que no atienden a los intereses ni de los educandos, ni de los agentes educativos ni del contexto social en el que tiene lugar la acción educativa. 


\section{REFERENCIAS BIBLIOGRÁFICAS}

Asensio, J. M.; García Carrasco, J.; Núñez Cubero, l. y Larrosa, J. (coords.) (2006) la vida emocional. Las emociones y la formación de la identidad humana. Barcelona, Ariel.

Aznar, P. y Gargallo, B. (1999) La teoría y la práctica educativa: problemas y propuestas, en AzNar, P. (coord.) Teoría de la educación. Un enfoque constructivista. Valencia, Tirant lo Blanch, 139-185.

BIRD, R. J. (2003) Chaos and life. Complexity and order in evolution and thought. New York, Columbia University Press.

Colom, A. J. (2001) Teoría del caos y educación (acerca de la reconceptualización del saber educativo). Revista española de pedagogía, 218, 5-24.

- (2002) La (de)construcción del conocimiento pedagógico. Barcelona, Paidós.

Colom, A. J. y MèLıch, J. C. (1994) Después de la modernidad. Nuevas filosofías de la educación. Barcelona, Paidós.

Colom, A. J. y NúÑez, L. (2001) Teoría de la educación. Madrid, Síntesis.

Conill, J. (1997) El poder de la mentira. Nietzsche y la política de la transvaloración. Madrid, Tecnos.

CORTINA, A. (2007) Ética de la razón cordial. Educar en la ciudadanía del siglo XXI. Oviedo, Nobel.

Cortina, A.; Escámez, J. y Pérez-Delgado, E. (1996) Un mundo de valores. Valencia, Generalitat Valenciana.

Escámez, J. (1992) La filosofía de la educación como praxis educativa, en VV.AA. Filosofía de la educación en Europa. Madrid, Dykinson, 135-147.

Finkielkraut, A. (1987) La derrota del pensamiento. Barcelona, Anagrama.

Gallego, D. J. y AnTón, H. (2007) ¿Aulas conflictivas? La opinión del profesorado. Madrid, Dykinson.

Gargallo, B. (2002) La teoría de la educación. Objeto, enfoques y contenidos. Teoría de la educación, 14, 19-46.

GozÁlvez, V. (2000) Inteligencia moral. Bilbao, Desclée de Brouwer.

- (2007) Nihilisme i posconvencionalitat, en Arenas, F.; Giancristofaro, L. y Stellino, P. (eds.) Nietzsche y la hermenéutica. Valencia, Nau llibres, 899-908.

GribBin, J. (2005) Deep simplicity: Bringing order to chaos and complexity. New York, Random House.

Habermas, J. (1989) El discurso filosófico de la modernidad. Madrid, Taurus.

- (2003) Acción comunicativa y razón sin trascendencia. Barcelona, Paidós.

Hargreaves, A. (1999) Profesorado, cultura y postmodernidad. Madrid, Morata.

Herder, J. G. (2007) La idea de humanidad, en Maestre, A. (ed.) ¿Qué es Ilustración? Madrid, Tecnos, 61-66.

IBÁÑez, E. A. (2008) Las teorías del caos, la complejidad y los sistemas. Rosario, Homo Sapiens Ediciones.

Lipovetsky, G. (1996) El crepúsculo del deber. Barcelona, Anagrama.

LYOTARD, J. F. (1986) La condición posmoderna. Madrid, Cátedra.

Maestre, A. (ed.) (2007) ¿Qué es la Ilustración? Madrid, Tecnos.

MÈLıch, J. C. (2008) Filosofía y educación en la postmodernidad, en Hoyos, G. (ed.) Filosofía de la educación. Madrid, Trotta, 35-53.

MÈLICH, J. C. y Bárcena, F. (1999) La palabra del otro. Una crítica del principio de autonomía en educación. Revista española de pedagogía, 214, 465-483. 
Naval, C. (2008) Teoría de la educación. Un análisis epistemológico. Pamplona, Eunsa. NieTzsche, F. (2005) Sobre verdad y mentira en sentido extramoral. Valencia, Diálogo.

- (2006) Así habló Zaratustra. Madrid, Alianza.

Núñez, L. y Romero, C. (2003) Pensar la educación. Conceptos y opciones fundamentales. Madrid, Pirámide.

Pérez, C. (2009) Valores y normas para la convivencia en el aula. Madrid, Eos.

PetTit, Ph. (1999) Republicanismo. Una teoría sobre la libertad y el gobierno. Barcelona, Paidós.

Reboul, O. (2009) Filosofía de la educación. Barcelona, Davinci.

Sanjuán, M. A. y Grebogi, C. (2010) Recent progress in controlling chaos. New Jersey, Worl Scientific.

Santos, M. A. y Guillaumín, A. (2006) Avances en complejidad y educación: Teoría y práctica. Barcelona, Octaedro.

Sebreli, J. J. (2007) El olvido de la razón. Barcelona, Debate.

Sen, A. (2000) Desarrollo y libertad. Barcelona, Planeta.

STROGATZ, S. (2004) SYNC: How order emerges from chaos in the universe, nature and daily life. New York, Theia Books.

Tejedor, C. y Bonete, E. (2006) ¿Debemos tolerarlo todo? Bilbao, Desclée de Brouwer.

TERRÉN, E. (1999) Educación y modernidad. Entre la utopia y la burocracia. Barcelona, Anthropos-Universidad da Coruña.

Todorov, T. (2007) El espiritu de la Ilustración. Galaxia Gutenberg, Círculo de lectores.

Vattimo, G. (2003) Nihilismo y emancipación. Barcelona, Paidós. 